\title{
PENYULUHAN KESEHATAN SEBAGAI UPAYA PENGENDALIAN HIPERTENSI PADA MASA NEW NORMAL DI DUSUN GUPAK WARAK YOGYAKARTA
}

\author{
R. Jaka Sarwadhamana1), Almira Dwi Yana P2), Ani Nurlinda ${ }^{3)}$, Ayatullah Al-Wajid', \\ Anna Laila $\mathbf{S}^{1}$, Siti Zakiyatul $\mathbf{F}^{1)}$ \\ 1)Program studi Administrasi Rumah Sakit, Universitas Alma Ata, Kota Yogyakarta, Yogyakarta, Indonesia \\ 2)Program Studi IImu Gizi, Universitas Alma Ata, Yogyakarta, Indonesia \\ 3)Mahasiswa Program Studi Pendidikan Agama Islam, Universitas Alma Ata, Yogyakarta, Indonesia \\ Corresponding author: R. Jaka Sarwadhamana \\ Email : jaka.sarwadhamana@almaata.ac.id
}

Diterima 15 November 2021, Disetujui 27 November 2021

\begin{abstract}
ABSTRAK
Hipertensi merupakan masalah kesehatan yang membutuhkan perhatian karena menyebabkan kematian yang tidak dapat diidentifikasi penyebabnya. Prevalensi Hipertensi yang ada di Indonesia dari tahun ke tahun mengalami peningkatan yang signifikan. Faktor utama penyakit Hipertensi di sebabkan oleh faktor pola hidup yang tidak sehat. Kegiatan pengabdian kepada masyarakat ini mempunyai tujuan untuk memberikan pemahaman kepada lansia agar dapat memahami dan mengetahui gejala hipertensi, faktor penyebab hipertensi, komplikasi dari penyakit hipertensi, dan cara menurunkan tekanan serta dapat membantu masyarakat dalam mengurangi angka peningkatan tekanan darah atau Hipertensi. Pelaksanaan kegiatan dilakukan di Dusun Gupak Warak, Desa Sendangsari, Bantul Yogyakarta. Kegiatan diikuti oleh 30 lansia dengan metode ceramah dan pemeriksaan kesehatan. Hasil evaluasi akhir dengan metode tanya jawab menujukan bahwa terjadinya peningkatan pemahaman dan pengetahauan yang dimiliki oleh lansia tentang hipertensi.
\end{abstract}

Kata kunci: hipertensi; penyuluhan kesehatan; lansia

\begin{abstract}
Hypertension is a health problem that requires attention because it causes death whose cause cannot be identified. The prevalence of hypertension in Indonesia from year to year has increased significantly. The main factor of hypertension is caused by unhealthy lifestyle factors. This community service activity has the aim of providing understanding to the elderly so that they can understand and know the symptoms of hypertension, the factors that cause hypertension, complications of hypertension, and how to reduce pressure and can help the community in reducing the increase in blood pressure or hypertension. The activity was carried out in Gupak Warak Hamlet, Sendangsari Village, Bantul Yogyakarta. The activity was attended by 30 elderly people with lecture methods and health checks. The results of the final evaluation using the question and answer method showed that there was an increase in the understanding and knowledge possessed by the elderly about hypertension
\end{abstract}

Kata kunci: hypertension; health education; elderly

\section{PENDAHULUAN}

Semakin bertambah umur seseorang semakin banyak pula penyakit yang munculdan sering diderita khususnya pada lansiaatau lanjut usia. Pada usia lanjut akan terjadiberbagai kemunduran pada organ tubuh,oleh sebab itu para lansia mudah sekaliterkena penyakit seperti hipertensi ( $\mathrm{Li}$ et al., 2013). Hipertensi adalah suatu keadaan dimana seseorang mengalami peningkatantekanan darah di atas normal yang mengakibatkan suplai oksigen dan nutrisi yang dibawa oleh darah terhambat sampai ke jaringan tubuh yang membutuhkannya (Smeltzer, S.C., Bare, B.G., Hinkle, J.L., \& Cheever, 2012).
Berdasarkan Joint National Committee (JNC VII) seorang dikatakan hipertensi apabila tekanan darahsistolik $>140 \mathrm{mmHg}$ dan diastolik $>90 \mathrm{mmHg}$ (Rachman, F., Julianti, H. P., \& Pramono, 2011). Nilai tekanan darah yang paling ideal adalah 115/75 mmHg (Agoes, 2011). Publikasi hasil penelitian yang dilakukan oleh Joint National Committee (JNC VII) menyimpulkan bahwa seseorang yang berusia 50 tahundengan tekanan darah sitolik lebih dari $>140 \mathrm{mmHg}$ lebih berisiko menderitapenyakit kardiovaskular daripada hipertensi diastolik. Risiko menderita penyakitkardiovaskular dimulai pada tekanan darah $115 / 75 \mathrm{mmHg}$, menambah 2 kali padasetiap penambahan $20 / 10 \mathrm{mmHg}$. Seseorang yang mempunyai tekanan darah 
normal pada usia 55 tahun, 90\%-nya berisiko menjadi hipertensi.

Menurut Riset Kesehatan Dasar tahun 2018 Kementerian Kesehatan Republik Indonesia, prevalensi hipertensi di Indonesia pada usia diatas 18 tahun mencapai $34,11 \%$. Prevalensi ini semakin bertambah seiring dengan bertambahnya usia. Data Riskesdas tersebut menyebutkan hipertensi sebagai penyebab kematian nomor 3 setelah stroke dan tuberkulosis, jumlahnya mencapai $6,8 \%$ dari proporsi penyebab kematian pada semua umur di Indonesia (Kementerian Kesehatan Republik Indonesia, 2018).

Profil Kesehatan Provinsi Daerah Istimewa Yogyakarta (DIY) tahun 2020 melaporkan bahwa pada banyak kasus kunjungan, penyakit hipertensi telah menjadi penyakit paling dominan kedua bagi kelompok keluarga di DIY (Dinas Kesehatan Yogyakarta, 2020). Di Indonesia, persentase penyakit hipertensi menurut kabupaten kota cukup bervariasi. Hasil Riset Kesehatan Daerah (Riskesdas 2018) menunjukkan bahwa propinsi DIY masuk dalam lima besar provinsi dengan kasus hipertensi terbanyak yang mencapai $32,86 \%$ dan sebanyak 29,564\% diantaranya adalah kelompok penduduk lanjut usia (Kementerian Kesehatan Republik Indonesia, 2018).

Penyakit hipertensi dapat menjadi faktor penyebab dari penyakit kronis, seperti terjadinya penyakit jantung, stroke, dan penyakit ginjal (Song, Yapei; Ma, Wei; Xiangren Yi; Wang, Shumei; Sun, 2013). Penyuluhan kesehatan menjadi hal penting bagi lansia sebagai upaya pengendalian tekanan darah agar tetap dalam kisaran normal (Notoatmodjo, 2013). Menurut WHO, memberikan pendidikan kesehatan mengenai pencegahan Tuberculosis kepada masyarakat atau kelompok dapat membentuk dan mempersiapkan masyarakat terhadap pencegahan primer penyakit hipertensi. Salah satu metode untuk memberikan pendidikan kesehatan adalah dengan menggunakan media yang baik serta sesuai dengan tujuan yang dicapai (World Health Organization, 2017).

Dengan mengetahui tentang penyebab penyakit Hipertensi, maka diharapkan angka penderita Hipertensi dapat berkurang. Dusun Gupak Warak yang terdapat di Desa Sendangsari, Kecamatan Pajangan, Bantul ini memiliki banyak masyarakat yang sudah masuk usia lansia yang di mana usia lansia menjadi salah satu faktor penyebab Hipertensi. Dilakukannya penyuluhan Hipertensi dapat membantu masyarakat Dusun Gupak Warak mengetahui faktor penyebab meningkatnya Hipertensi dan Cara pencegahan peningkatan tekanan darah.

\section{METODE}

Kegiatan pengabdian ini dilaksanakan di Dusun Gupak Warak yang terdapat di Desa Sendangsari, Kecamatan Pajangan, Bantul Yogyakarta. Kegiatan dilaksanakan pada tanggal 12 Oktober 2021. Sasaran kegiatan ini adalah lansia yang tinggal di wilayah tersebut yang berjumlah 30 orang. Kegiatan ini dilakukan melalui pemberian penyuluhan kesehatan dengan metode ceramah, tanya jawab dan diskusi. Tahapan yang dilaksanakan dalam kegiatan ini meliputi:

1. Persiapan kegiatan: Koordinasi dengan Kepala Pusksmas dan Kepala Dukuh Gupak Warak untuk menentukan waktu yang tepat dalam memberikan penyuluhan kesehatan.

2. Penjelasan maksud dan tujuan kegiatan serta pengukuran hipertensi mealalui pemeriksaan kesehatan

3. Menyampaikan materi penyuluhan kesehatan dengan metode ceramah tentang penyakit hipertensi kepada peserta.

4. Melakukan feedback (diskusi dan tanya jawab) terkait materi yang telah disampaikan.

\section{HASIL DAN PEMBAHASAN Hasil}

Pelaksanaan penyuluhan kesehatan dilaskanakan pada hari selasa tanggal 12 Oktober 2021 yang bertempat di Dusun Gupak Warak. Kegiatan yang bertemakan "Penyuluhan Kesehatan Sebagai Upaya Pencegahan Hipertensi Pada Lansia" di hadiri oleh 30 peserta yang merupakan lansia di Dusun tersebut.

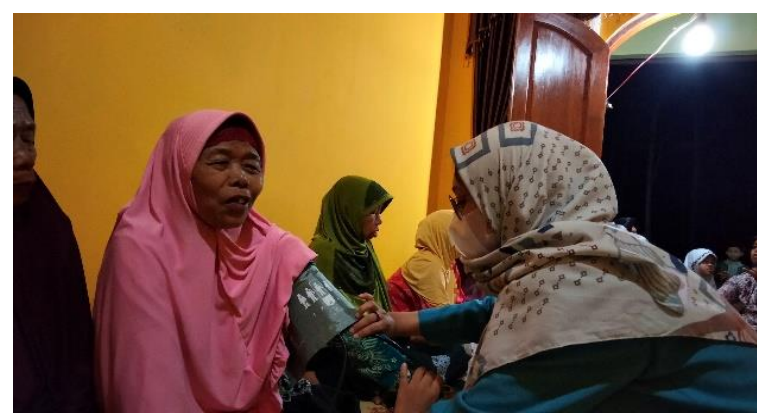

Gambar 1. Pemeriksaan Kesehatan Lansia Dusun Gupak Warak

Acara di awali dengan sambutan dan penjalasan kegiatan kepada semua peserta dan dilanjutkan dengan pengukuran tekanan darah sebelum di berikannya materi penyuluhan tentang hipertensi. Kegiatan diakhiri dengan diskusi dan tanya jawab tentang penyakit hipertensi. Berdasarkan hasit tanya jawab dengan peserta, didapatkan bahwa terjadinya peningkatan pengetahauan dan pemahaman 
peserta hipertensi yang di lihat pada antusiannya peserta dalam proses diskusi.

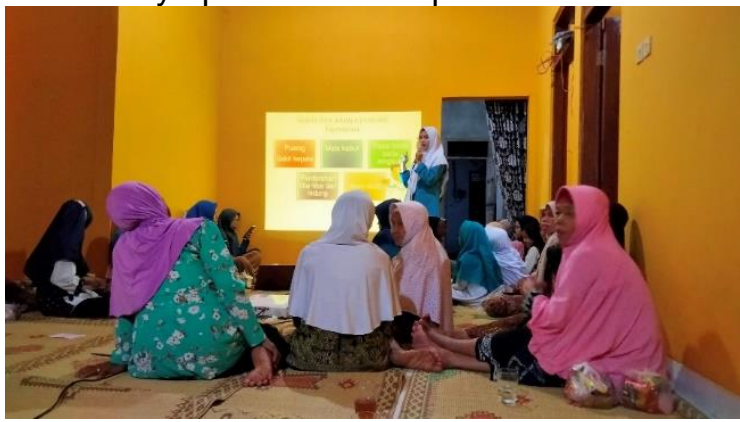

Gambar 2. Penyuluhan Kesehatan dan Diskusi Tentang Hipertensi di Dusun Gupawarak

\section{Pembahasan}

Kegiatan penyuluhan kesehatan diawali dengan koordinasi dengann pihak Puskesmas dan Kepala Dukuh Dusun Gupawarak untuk mendiskusikan rincian acara yang akan dilaksanakan. Kegiatan selanjutnya dilakukan dengan penjelasan tujuan kegiatan kepada peserta serta dilanjutkan dengan pemeriksaaan kesehatan hipertensi seperti pada gambar 1 . Hasil pemeriksaan awal menunjukan bahwa sebagian besar responden mengalami prehipertensi yaitu tekanan darah berada pada rentang 120-139 untuk tekanan sistolik dan 8089 untuk tekanan diastolik. Hipertensi pada usia lanjut perlu mendapat perhatian yang lebih serius (Huang et al., 2011). Selain elastisitas pembuluh darah penderita yang menurun, kerja jantung umumnya pun sudah mulai terganggu (Delacroix \& Chokka, 2014). Hipertensi pada usia lanjut juga selalu membawa pengaruh buruk karena penyakitnya "tidak jinak". Pada usia lanjut bila tekanan darahnya, baik sistolik maupun diastolik, meninggi dalam waktu yang tidak terlalu lama maka harus dicurigai adanya pembuluh darah ginjal yang terganggu. Hal ini dikenal sebagai hipertensi renovaskuler aterosklerotik (Kreisel et al., 2021).

$$
\text { Kegiatan selanjutnya yaitu }
$$

Menyampaikan materi penyuluhan kesehatan dengan metode ceramah tentang hipertensi. Materi penyuluhan berisikan penjelasan tentang gejala hipertensi, faktor penyebab hipertensi, komplikasi dari penyakit hipertensi, dan cara menurunkan tekanan darah. Kegiatan penyuluhan juga dibarengi dengan kegiatan diskusi seperti pada gambar 2. Hasil diskusi menujukan bahwa banyak lansia yang mempunyai tekanan darah yang tinggi tetapi masyarakat banyak yang belum memahami bahwa tekanan darah tinggi itu adalah Hipertensi. Masyarakat masih sering memakan makanan tinggi garam dan makanan manis lainnya seperti dalam air teh. Hipertensi merupakan masalah yang serius di dalam kesehatan yang di mana merupakan akar penyakit dari stroke, jantung dan gagal ginjal (Gu, et all, 2020) .

Dalam sesi tanya jawab dan evaluasi setelah penyampaian materi, banyak warga yang mengajukan pertanyaan tentang bagaimana cara mencegah dan mengendalikan hipertensi, gaya hidup yang perlu dilakukan, makanan yang boleh dan tidak boleh dikonsumsi. Hal ini menunjukkan bahwa masyarakat sangat peduli dengan kesehatan dan masyarakat membutuhkan informasiinformasi mengenai masalah kesehatan. Nelwan, (2019) menjelaskan bahwa faktor yang mempengaruhi terjadinya hipertensi adalah pola hidup yang kurang baik seperti kebiasaan merokok mengkonsumsi alkohol dan kebiasaaan jarang berolahraga. Aung et al., (2012) dalam penelitiannnya menyampaikan bahwa kegiatan pendidikan kesehatan terhadap masyarakat khususnya lansia telah menunjukan strategi yang tepat untuk mendorong masyarakat dalam belajar dan berpartisipasi dalam pengobatan hipertensi.

\section{SIMPULAN DAN SARAN}

Hasil kegiatan penyuluhan kesehatan kepada masyarakat yang telah dilakukan dapat di simpulkan bahwa terjadi peningkatan pemahaman masayrakat dalam pencegahan dampak buruk hipertensi. penyuluhan dengan berbagai metode yang salah satunya dengan metode ceramah dengan penggunaan media leaflet diperlukan dalam upaya preventif hipertension di tingkat masyarakat. Diharapkan pihak Puskesmas, Kader posyandu dan Instansi terkait dapat melakukan kerja sama lanjutan seperti membentuk posyandu lansia di masingmasing dusun dengan di integrasikan melalui upaya pemeriksaan kesehatan dan penyuluhan kesehatan.

\section{UCAPAN TERIMAKASIH}

Penulis menyampaikan terimakasih kepada semua pihak yang telah membantu dalam pelaksanaan kegiatan penyuluhan kesehatan ini. Secara khusus penulis ingin berterimakasih kepada Universitas Alma Ata yang telah menyelanggarakan KKN Tematik sebagai bentuk Tridharma perngguruan tinggi dalam bentuk pengabdian kepada masyarakat secara tepat.

\section{DAFTAR RUJUKAN}

Agoes, H. A. (2011). Penyakit Diusia Tua. EGC. Aung, M. N., Lorga, T., Srikrajang, J., Promtingkran, N., Kreuangchai, S., Tonpanya, W., Vivarakanon, P., Jaiin, P., Praipaksin, N., \& Payaprom, A. (2012). Assessing Awareness And 
Knowledge Of Hypertension In An AtRisk Population In The Karen Ethnic Rural Community, Thasongyang, Thailand. International Journal of General Medicine, 5, 553-561. https://doi.org/10.2147/IJGM.S29406

Delacroix, S., \& Chokka, R. G. (2014). Hypertension: Pathophysiology and Treatment. Journal of Neurology \& Neurophysiology, $5(6)$. https://doi.org/10.4172/21559562.1000250

Dinas Kesehatan Yogyakarta. (2020). Profil Kesehatan Tahun 2020 Kota Yogyakarta (Data Tahun 2019).

Gu, X., Fang, X., Ji, X., Tang, Z., Wang, C., Guan, S., ... \& Zhang, Z. (2020). Kidney Dysfunction Is Associated With Risk Of Cardiovascular Events In Middle-Aged And Elderly Population With Hypertension: A 5-Year CommunityBased Cohort Study In China. Clinical Nephrology, 93(3), 130.

Huang, J., Zhang, W., Li, X., Zhou, J., Gao, Y., Cai, Y., Lin, X., Lai, X., Wu, Y., Huang, B., Chen, Z., Zhu, S., Chen, Z., Lin, Y., \& Chen, G. (2011). Analysis Of The Prevalence And Risk Factors Of Hypertension In The She Population In Fujian, China. Kidney and Blood Pressure Research, 34(2), 69-74. https://doi.org/10.1159/000323164

Kementerian Kesehatan Republik Indonesia. (2018). Laporan Nasional Riset Kesehatan Dasar. In Kementrian kesehatan RI.

https://dinkes.kalbarprov.go.id/wpcontent/uploads/2019/03/LaporanRiskesdas-2018-Nasional.pdf

Kreisel, W., Lazaro, A., Trebicka, J., Perdekamp, M. G., Schmitt-Graeff, A., \& Deibert, P. (2021). Cyclic gmp in liver cirrhosis-role in pathophysiology of portal hypertension and therapeutic implications. International Journal of Molecular Sciences, 19.

Li, X., Ning, N., Hao, Y., Sun, H., Gao, L., Jiao, M., Wu, Q., \& Quan, H. (2013). Health literacy in rural areas of China: hypertension knowledge survey. International Journal of Environmental Research and Public Health, 10(3), 1125-1138.

https://doi.org/10.3390/ijerph10031125

Nelwan, J. E. (2019). Pengaruh Penyuluhan Kesehatan Terhadap Perubahan Pengetahuan Masyarakat Tentang Hipertensi Di Kota Manado. Journal $\begin{array}{lll}P H W B, & 1(2), & 1-7 .\end{array}$ http://ejournalhealth.com
Notoatmodjo. (2013). Promosi dan Perilaku Kesehatan. Renika Cipta.

Rachman, F., Julianti, H. P., \& Pramono, D. (2011). Berbagai Faktor yang Berhubungan dengan Kejadian Hipertensi pada Lansia (Studi Kasus di Rumah Sakit Dr. Kariadi Semarang). Universitas Diponegoro, Semarang.

Smeltzer, S.C., Bare, B.G., Hinkle, J.L., \& Cheever, K. . (2012). Textbook of Medical Surgical Nursing. Lippincott Williams \& Wilkins.

Song, Yapei; Ma, Wei; Xiangren Yi; Wang, Shumei; Sun, X. et al. (2013). Chronic Diseases Knowledge and Related Factors among the Elderly in Jinan, China. PLoS One; San Francisco, 8(6). https://doi.org/DOI:10.1371/journal.pon e.0068599

World Health Organization. (2017). Health Education. Retrieved November 30, 2017.

http://www.who.int/topics/health_educat ion/en/ 